\title{
Reference
}

Liang, J. (1984). Dimensions of the life satisfaction index: a structural formation, Journal of Gerontology, 39, 61 3-622.

Faculty of Social Studies, The Open University, Milton Keynes, Buckinghamshire

\section{Grandparents Who Parent}

\section{Mary Jean Etten}

M. P. Jendrek, Grandparents who parent their grandchildren: circumstances and decisions, The Gerontologist, 34, 2 (1994), 206-2 16.

Grandparents who parent a grandchild in the United States have grown at a phenomenal rate over the last decade. The Census Bureau estimated that in 1991 about 3.3 million children resided with their grandparents, an increase of 44 per cent since the 1980 census. This number only includes grandchildren who actually lived in the grandparents' home, not those where the grandparent lived in their son or daughter's home and assumed care of the grandchild (Saluter, I992).

The theoretical context of grandparenting is examined regarding the appropriateness of the role based on life role expectations. Timedisordered roles emerge when expected family, age-set, or work roles are out of harmony with each other. Two types have been identified, 'age-stage violation' and 'fluid-cycle violation'. Several researchers have described 'age-stage violation' as a departure from the association of given life events and behaviour with specific age ranges, which some see as part of the cultural fabric of a people. To grandparent grandchildren is not an appropriate role from this perspective. In contrast, 'fluid-cycle violation' is put forward as a more plausible description by other researchers who see a blurring of the associations between certain periods of life and chronological age.

Three types of grandparent role were defined. Legal grandparents have legal custody of a grandchild, the right to make decisions regarding the child's discipline, education, and medical care, and also physical custody, the right to have the child live with them, including the responsibility of daily care. The second type is day-care grandparents: they provide care for the grandchild for extended periods, assuming the parenting role between daycare and custody, but do not have legal custody. The third type is live-with grandparents: 
they assume most or all responsibility for the daily physical care needs of the grandchild, but do not have legal custody. Two types of live-with grandparents have been identified: where one or both of the child's parents also live with the grandparent, and otherwise.

This study used both qualitative and quantitative data to examine the conditions which lead grandparents to take over the grandchildren's parenting role. A non-probability sample of I I 4 grandparents giving continued care to grandchildren was obtained from courts and by advertising in or near Butler County, Ohio. Those who volunteered for the study were interviewed to exclude those who did not provide continued care to a grandchild. A second-stage in-depth interview focused on one grandchild and contained six sections. The three used in this study were: (I) the type of care that the grandparent was giving and had previously given; (2) why the grandparent gave regular care to the grandchild; and (3) the decision to give care and whether grandparents had been pressured so to do. Interviews lasted from onehalf to three hours and most were conducted by telephone.

The sample included 36 'custodial', 26 'living-with' and 52 'daycare' grandparents. Ninety-six per cent of the sample were White, $97 \%$ were female, and the mean age was $5^{6}$ years. Fifty-five per cent did not work outside the home. Education levels varied from seventh grade to Masters degrees with a median of about one year of college. Slightly more than half of the grandchildren studied were male and $67 \%$ were maternal grandchildren. Grandparents cared for their grandchildren for diverse reasons. Severe problems in the nuclear family of the grandchild was the most frequent reason for assuming custodial care of the grandchild. Usually the child's home situation had become dysfunctional because the mother was on drugs or alcohol or was mentally ill. Grandparents then offered to care for the grandchild to provide a healthy, safe life, often out of a fear that the child would be placed in a foster home. Alongside their willingness to care for the grandchild, grandparents deeply wished that their own child could adopt a more normal life and assume responsibility for the grandchild. Living-with grandparents' responsibilities of parenting reflected either the custodial or day-care roles. Most of the children's parents were either living at home with their own parent or needed help. Reasons cited for grandparents assuming this role included: the parent(s) being financially needy or working full-time, emotional problems of the mother, single status of the parent, and the preference to provide care rather than allowing others to do so. Day-care grandparents principally provided care to help the grandchild's nuclear family (which was usually functional). Care was restricted to physical needs and it was 
usually given for a limited period. The decision to provide the care was often considered automatic: grandparents indicated that it had to be this way, there was no choice, or that they did what they had to do.

Many took on the parenting role because another need in the child's family prohibited parents from raising their own children. These needs included divorce, unemployment, illness, drug or alcohol use, and single parenting. Other reasons were less urgent but the grandparents nonetheless played a very important role in supporting their own children's family network.

E. B. Dowdell, Caregiver burden: grandparents raising their high risk grandchildren, Fournal of Psychosocial Nursing, 33, 3 (1995), $27-30$.

It is estimated that the primary care of grandchildren is assumed by three to four million grandmothers and great-grandmothers (Martin, I99I). Research on this rapidly emerging social change is increasing, and this study focused on the relationships between the care-giver burden of grandparents who care for grandchildren and the caregiver's physical health. Care-giver burden describes the social, psychological, emotional, physical and financial problems experienced by family care-givers. One hundred and fifty-four grandmothers who had the primary responsibility to care for one or more grandchildren were the subjects of this study. They were married, single, separated, divorced and widowed, and they cared for a grandchild in their home for six months or longer. The median age was 54.8 years and the range from 31 to 77 years. Sixty-eight per cent were maternal grandmothers, $5^{8 \%}$ African-American, $38 \%$ Caucasian, two were native American and one Hispanic. About half were married and $39 \%$ were high school graduates. The grandchildren ranged in age from 6 months to 15 years, with $59 \%$ aged 5 years or younger.

The majority $(86 \%)$ of the grandchildren were placed in the grandmother's care by Court Order or by the Department of Social Services. The reason for $80 \%$ of these placements was drug use; other reasons included mental illness, incarcerations and parental death. The total number of grandchildren cared for by a grandmother ranged from one to nine. The 'Caregiver Reactions Assessment' was used to assess caregiver burden. (Given, Given, Stommel, Collins, King and Franklin, 1992). Composed of 24 items, it measures the subjective and objective reactions and strains of the caregiver. It includes five subscales: care-giver esteem, level of family support, impact on finances, 
impact on schedule, and impact on care-giver health. The 'Caregiver Physical Health Questionnaire' adapted from the OARS was used to assess the physical health of the caregiver (Given, I986).

The five sub-scales of care-giver burden correlated strongly with high levels of stress. Grandmothers who were not married stated that they had less support from the family and were in poorer health than those who were married. Finances too were stressful for the grandparents, since many received neither public money for grandchild care nor utilities nor food stamps. Sixty-one per cent of the children received some public assistance. Forty-five per cent of the grandmothers viewed themselves as ill or having a physical problem such as heart disease, hypertension, arthritis, cancer, diabetes or asthma. Grandmothers who received the support of their spouses also believed that they had more family support and this positively influenced their perception of their health and degree of family support. One-third of the grandchildren were in ill health, which increased the stress level of the grandmother. Those who cared for sick or young grandchildren were the most likely to attend a support group. Considering the lack of finances and family support as well as ill health, the grandmothers believed that caring for a grandchild had a negative influence on their health, finances and daily activities.

The author argues that nurses are the key professionals to assess, to intervene and to support both grandchild and grandmother. Grandmother care-giver and grandchild assessments are recommended, including a care-giver burden and physical assessment for grandmothers who care for grandchildren. Nurses are seen as professionals who can develop support systems for women who assume the care of grandchildren. Further research is suggested into ways to keep children off drugs, the most often cited reason for grandparents needing to care for their children's children.

\section{COMMENT}

Aldous (1995) points out that only in the past half-century have sufficient numbers of persons lived long enough to become grandparents. These people are rarely frail. Both studies confirm the rapid change in child-rearing roles in the United States and the growing number of living grandparents. During 1980-1991, there was a $44 \%$ increase in the number of grandparents who were parenting their grandchildren. Increasing numbers of older persons of various ethnic groups and the White majority in the United States are now being challenged to take on the role of parenting grandchildren. The increase 
in single parent families, divorce and separation also lead to the need for assistance with parenting. Social problems such as drug and alcohol addiction, and mental instability are major reasons cited for parents not being able to raise their own children. Lastly, help with child care arises from two parents working and the need to cut down on child care costs.

These changes in child rearing practices are likely to affect the family system as we have known it. Parenting grandchildren has become such a visible issue in the United States that there is a proliferation of articles in magazines such as Modern Maturity. The American Association of Retired Persons has established a Grandparent Information Center, as a resource to assist grandparents in coping with this new role. Support groups and work-shops are also offered. Even health departments are issuing brochures specifically for grandparents on the care of young children citing good child health care practices and the need for immunizations and medical checkups. Perhaps the time-honoured developmental tasks of middle and older age will be challenged by these trends, and new societal norms or role expectations may emerge. More research is needed to investigate the great range of problematic and dynamic issues.

\section{References}

Aldous, J. 1995. New views of grandparents in intergenarational context. Journal of Family Issues, 16, 104-1 22.

Saluter, A. F. 1992. Marital Status and Living Arrangements: March 1991. Current Population Reports, Population Characteristics, Series P-20, No. 461 , United States Government Printing Office, Washington, D.C.

Nursing Program,

St Petersburg Junior College,

St Petersburg, Florida

\section{Payments for Care and Retirement Schemes}

Tony Maltby

Clare Ungerson, Gender, cash and informal care, Journal of Social Policy, 24 (I) (1 995), $3^{\mathrm{I}-52}$.

This article considers the important issue of 'payments for care' from a British perspective but with a European focus. The issue of 'payments for care' is of particular significance, the author argues, because with rising numbers of older people, most countries in Europe are following 